\title{
Missões no Alto Amazonas: índios e jesuítas em Maynas ${ }^{1}$
}

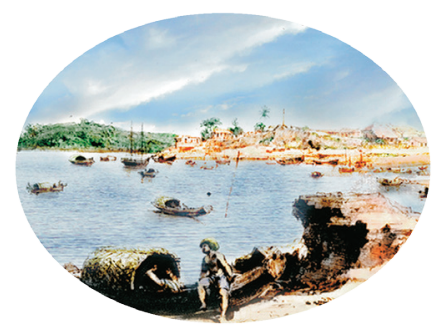

Maria Cristina Bohn Martins*

\section{Resumo}

Este trabalho analisa o trabalho de evangelização dos jesuítas mediante a constituição de pueblos de índios em uma área em particular, qual seja, a do Alto Amazonas, onde se constituiu a chamada Missão de Maynas. Nesse sentido buscamos especialmente revisar algumas contradições que se estabelecem entre os múltiplos sentidos da missão.

Palavras-chave: Missão de Maynas; jesuítas; índios.

\begin{abstract}
This article studies a particular area in South América, the "High Amazonas", where the Jesuits have found various "pueblos de indios" in the Maynas's Mision. The text analyzes some contradictions involving the meanings of this work.
\end{abstract}

Keywords: Maynas missions; jesuits; indians.

\footnotetext{
* Bolsista Produtividade do CNPq. Doutora em História pela Pontifícia Universidade Católica do Rio Grande do Sul (História Ibero-Americana - 1999). Atualmente é professora titular da UNISINOS.
} 


\section{Introdução}

Refletir sobre a experiência das missões religiosas jesuíticas na América Colonial requer, necessariamente, pensá-las sob variados aspectos. De fato, os pueblos que estiveram assistidos pela companhia foram, sob a perspectiva da ordem, um modelo de evangelização, modelo este que esteve baseado na presença permanente dos religiosos junto às populações a serem convertidas e doutrinadas. Todavia, observadas sob outro ângulo, as reduções podem ser definidas como uma estratégia de "civilização", uma vez que se entendia necessário transformar "gente rústica em cristãos civilizados com a contínua pregação do evangelho", segundo expressou o padre Antonio Ruiz de Montoya em 1639 (1985, p. 20).

Isto é, era preciso conduzir os índios às pautas de uma vida "política e humana" como requisito para o trabalho da evangelização. No âmbito desta transformação, era preciso que os nativos abandonassem práticas como a poligamia, as festas de bebedeira ou as guerras. Sobre os índios amazônicos, os jesuítas registram como dificuldades a serem superadas, por exemplo, o fato de serem "criados en la vida ancha y ociosa de los montes, sin sujeción a nadie, amicíssimos de passearse, y de andar de unas partes á otras" (FIGUEROA, 1986 [1661], 163-164).

Observadas sob a perspectiva do Império, as reduções foram instrumento de controle de certos territórios de fronteira, especialmente em regiões nas quais os poderes coloniais chegavam apenas escassamente. Atenderam, pois, nesse sentido, a necessidade de concentração dos índios em povoados estáveis a fim de facilitar o seu controle e a cobrança de tributos.

Sabemos que, nas áreas americanas ocupadas por povos sedentários e organizados em Estados hierárquicos, baseados na exploração do trabalho e na produção de excedentes, os espanhóis transformaram os antigos sistemas de tributos em seu favor. Esse foi o caso do México-Tenochtitlán e do Tawantinsuyu. Contudo, os intricados processos que permitiram esse arranjo nas áreas dos antigos "impérios" indígenas, eram de difícil aplicação para além de suas fronteiras, naquelas regiões em que os indígenas - logo qualificados como "bravios" - mostravam-se refratários aos sistemas de trabalho compulsório introduzidos pelos ocidentais.

Serão estas as áreas preferenciais para o estabelecimento das 
"misiones" ou "reduciones", isto é, das novas comunidades em que os índios eram realocados por sacerdotes que deveriam doutriná-los e prepará-los para seu papel na nova ordem colonial (KERN \& JACKSON, 2006, p.11). Muitas vezes, a colaboração entre os religiosos e os agentes do Estado era um elemento fundamental para a constituição dos "pueblos de indios", garantindo aos primeiros as condições necessárias de entrada e "pacificação" dos grupos menos dispostos a recebê-los. Isso não deve fazer crer que, em diversas oportunidades, não seja possível perceber profundas discordâncias entre os propósitos dos padres e os interesses dos colonizadores, situação que torna complexa as tentativas de definições mais gerais para experiências que, da Patagônia à Califórnia, assumiram contornos distintos. Não há dúvida de que, mesmo no âmbito das reduções que estiveram sob a assistência de padres da Sociedade de Jesus, ocorressem diferenças importantes, com singularidades ligadas, tanto às particularidades dos processos regionais, quanto aos vários grupos indígenas envolvidos.

Nesse trabalho, analisando uma área em particular, qual seja, a do Alto Amazonas, onde se constituiu a chamada Missão de Maynas, ${ }^{2}$ pretendemos revisar algumas contradições que se estabelecem entre os múltiplos sentidos da missão.

\section{Maynas no Alto Amazonas}

O espaço em que se desenvolveram as chamadas Missões de Maynas corresponde, hoje, a uma imensa região na Amazônia Ocidental, abrangendo territórios do Oeste do Brasil, Sul do Equador, sul da Colômbia e Norte do Peru, e que era habitada por uma grande diversidade de grupos indígenas ao tempo em que se iniciou a colonização espanhola na área. As missões que os jesuítas desenvolveram nesta terra a partir dos inícios do século XVII receberam tal denominação em virtude do nome pelo qual era conhecido o grupo que foi o primeiro objeto de suas investidas na área.

A carta ânua de 1595 avalia positivamente as características das terras em que os padres iniciavam seu trabalho dizendo que "la región es fértil, amena y abundante de toda clase de buenos alimentos". Sobre os habitantes, a carta informa que "son (...) de elevada estatura y cuerpo robusto, que viven cerca del Marañón, y de otros ríos que en el deságuan, y forman numerosas naciones”. 
Depois, indicando que se tratava de uma impressão primeira, que era conferida pelas vestimentas e aparência exterior dos índios, o documento assinala que os maynas pareciam ser "muy tratables de índole aplacible" (apud: SANTOS, 1992, p. 224). A conclusão do autor da carta não é de todo incomum, e não raras vezes os corpos nus dos índios foram identificados como signos evidentes da sua barbárie.

A missão começou por obra dos jesuítas da Província de Quito, ${ }^{3}$ a partir do envio, em 1638, dos padres Gaspar de Cugia e Lucas de la Cueva ${ }^{4}$ para a cidade de "San Francisco de Borja", "única frontera y cabeza en este Gobierno", a fim de ajudar na pacificação de índios maynas rebelados (FIGUEROA, 1986 [1661], p. 154). Portanto, a exemplo de outros espaços, essas reduções deveriam constituir-se em um instrumento de pacificação do território e de sujeição dos índios aos poderes civis e espirituais. Em 1767, quando da promulgação da Pragmática Sanção que expulsava a Companhia de Jesus da Espanha e de seus territórios coloniais, o número de "pueblos de índios" aí fundados alcançava a cifra de cento de setenta e dois (entre reduções e anexos ${ }^{5}$ ). $O$ dado contudo, não deve fazer elidir que as fundações eram instáveis, e muitos povoados eram destruídos ou abandonados por fatores diversos.

Segundo dados colhidos por Angel Santos, em 1767 havia doze reduções na chamada "Misión Alta del Marañón", quatro outras estavam no Pastaza, onze na "Misión Baja del Marañón" e seis nos rios Napo e Aguarico. Como povoados anexos à missão de Santa Cruz de Lamas, encontravam-se "Archidona" e "Puerto del Napo". "En total, cuatro pueblos hispanizados, com sus respectivos anejos de índios, y 32 reducciones con 19.234 almas" (apud: SANTOS, 1992, p. 224).

Vários fatores explicam o fato de que as missões não alcançassem estabilidade e permanência, e que não tenham congregado populações maiores e mais constantes. Entre eles estão as enfermidades e pragas, altíssimas taxas de mortalidade infantil, levantes violentos contra os religiosos ou o abandono do povoado por parte de seus habitantes que regressavam para a vida nos "montes", isto é, nas matas. As investidas dos luso-brasileiros que aprisionavam não poucos índios, e ainda a desconfiança contra os padres - que se apresentavam como seus defensores e interlocutores diante do mundo colonial - também contribuíram para definir o quadro apontado.

Sabemos efetivamente que, no contexto da colonização hispânica da América, a "missão por redução" abrigava um projeto civilizador e evangelizador. 
Entretanto, se a organização dos índios em "pueblos" apresentava-se como expediente necessário para viabilizar a evangelização, ele também facilitava sua integração ao sistema colonial, concentrando mão de obra a serviço dos colonos especialmente através da prática da "encomienda". ${ }^{6}$

As "Ordenanzas sobre Descubrimientos" de Felipe II (1573) haviam inclusive atribuído a responsabilidade sobre a pacificação das regiões fronteiriças aos missionários, que deveriam fazer-se seguir, sempre que necessário, de pequenas escoltas ou guarnições militares, para proteção sua e dos índios que os acompanhassem (BOXER, 1978, p. 93).

O princípio de "congregar en pueblos" era, contudo, muito amplo, assumindo nuances diferenciadas segundo as situações históricas que lhe diziam respeito. Sobre isto, Bartomeu Meliá (1989, p. 22) lembra que:

\begin{abstract}
Nas Leis de Índias há um projeto de redução, porém na história da América hispânica existem muitas reduções, diferentes entre si. Substrato indígena, sistema econômico regional, ordem religiosa a qual pertenciam os missionários, estes e outros são os fatores históricos que determinam a forma concreta da redução.
\end{abstract}

\title{
1.10 início da Missão e o informe do padre Figueroa
}

As circunstâncias que marcam os inícios das missões de Maynas, as especificidades do projeto catequizador jesuítico na região, e as relações que se travavam entre índios, espanhóis ${ }^{7}$ e religiosos neste momento, estão narradas com grande riqueza de dados no Informe redigido pelo padre Francisco de Figueroa $^{8}$, entre 1659 e 1661. Seu texto é uma das principais fontes conhecidas para o estudo das primeiras décadas de existência dos povoados. Além das ricas e detalhadas impressões do próprio Figueroa, encontram-se aí, interpostas ao texto, cartas e escritos de outros missionários.

Figueroa é enviado para a missão a fim de contribuir com o trabalho iniciado por seus irmãos de Ordem e que trabalhavam com maynas e jeberos. A presença espanhola na área, cedo tinha instalado um ambiente de intensa conflitividade entre os primeiros e os poucos brancos então estabelecidos na região. Buscando ouro nos rios, os espanhóis haviam marcado uma incipiente 
presença, fazendo surgir um conjunto de acanhadas povoações, tais como Loja, Zamora, Santiago de la Montaña e Santa Maria de Nieves ${ }^{9}$ entre outras, algumas tão pequenas que contavam com menos de uma centena de povoadores.

A expressão "cidades" que era utilizada para qualificar estes povoados não deve nos levar a superestimar a importância material destas localidades. De fato, se ela revela bem o peso cultural do modelo urbanístico entre os espanhóis, "traduz mal a realidade física desses vilarejos sórdidos e efêmeros" (TAYLOR, 1992, p. 217).

A partir deles, os colonizadores entravam na mata para "sacar pieças", bem como para "reprimir las insolencias y daños que hacían los maynas" às suas cidades, nas quais, "por guardarse de sus imbaçiones se veían obligados a vivir con contínuas centinelas y defenderse de sus armadillas y emboscadas" (FIGUEROA, 1986 [1661], p. 160). Em 1616 um grupo destes índios será contatado por espanhóis que buscavam mão de obra para o trabalho de buscar ouro nas areias dos rios. A "pacificação" destes maynas, acabou sendo incentivo para que o governador Diego Vaca de la Vega solicitasse a permissão ${ }^{10}$ para fundar a cidade de San Francisco de Borja, assentada (1619) na margem esquerda do Marañón, não longe de Santiago de la Montaña e de Santa Maria de Nieves.

As relações que se estabelecem entre povoadores espanhóis e habitantes indígenas da região, não foram aí diferentes daquelas observadas em outros espaços da colonização hispânica, isto é, prevaleceram formas de sujeição baseadas na coerção e na imposição do trabalho encomendado:

Con sola esta província de indios maynas el Gobiernador y Capitán General D. Diego Vaca fundó la ciudad de San Francisco de Borja (..) haziéndola cabeça de esta gobernación... Y señalóle hasta veinte y quatro encomenderos, haziendo y repartiendo otras tantas encomiendas entre ellos, de todos los indios maynas que son los que an servido y sustentado con su servicio y tributos à la ciudad y sus vecinos (FIGUEROA, 1986 [1661], p. 159-160).

O quadro assim descrito em 1661 sobre a situação em que se encontravam os nativos é nada menos que dramático. De acordo com o documento escrito 
pelo jesuíta, ordinariamente saíam grupos de Borja em busca de índios fugitivos. A maior parte dos capturados morria logo ao chegar à cidade; os que permanecem vivos,

[...] tanto se esterilizan en este territorio, donde hay poco multíplico y logro de sus criaturas que les nacen, quizá por no tener sus comidas en abundancia y verse en sujeción, sin libertad y vida holgazana en que se crían y connaturalizan en estas tierras, siéndoles la sujeción contra su natural para la procreación, como se ve en las aves silvestres que, cogidas ó enjauladas, se esterilizan (FIGUEROA, 1986 [1661], p. 165).

Uma combinação altamente explosiva de doenças ${ }^{11}$, brutalidades e excesso de trabalho a que estavam submetidos, motivou, em 1635, uma desesperada rebelião dos maynas. A resposta do governador não se fez esperar: uma tropa de brancos, e de "índios amigos", perseguiu os rebelados em fuga, capturando e "justiçando" suas principais lideranças. Os demais foram reconduzidos para Borja e para Loja e escravizados.

É nesse contexto de crise que as autoridades locais solicitam ao Provincial dos jesuítas o envio de padres para auxiliar na pacificação da área. Gaspar de Cugia e Lucas de la Cueva chegaram a Borja em fevereiro de 1638, encontrando uma situação que lhes pareceu desoladora. Segundo eles, os "quatro ó cinco curas" que tinham estado aí antes deles, não haviam obtido sucesso na catequese dos índios. Os batizados eram feitos sem que nenhuma instrução cristã os houvesse preparado para receber o sacramento e, muitas vezes, não havia nenhum registro a seu respeito, pelo que muitos batismos tiveram que ser revalidados. "Así lo mostraban con la total ignorancia de todo, que no savían otra cosa sino sus ritos y fábulas bárbaras que heredaron de sus antepasados ...”(FIGUEROA, 1986 [1661], p. 161)..$^{12}$

Os padres primariamente ${ }^{13}$ conduziram missões volantes, isto é, itinerantes, dirigindo-se às populações repartidas entre as 24 encomiendas da região, "en puestos distantes (...) de que se aumentava el travajo, (...) pues no se podian cathequizar todos juntos, sino cada (...) pueblecillo de por sí, deteniéndo-se en cada uno conforme (...) la necesidad que tenian” 
(FIGUEROA, 1986 [1661], p. 162).

Embora avaliassem que a diversidade das línguas, a "rudeza" dos índios, assim como seu nomadismo ${ }^{14}$ fossem obstáculos poderosos para a catequese e conversão, os missionários não deixam de compreender e registrar que a violenta dominação exercida pelos espanhóis era um dado fundamental neste processo.

La causa es el irse los maynas frecuentemente, ó por travajo y malos tratamientos que les dan los españoles, ó por hambre, y no tener en sus pueblos y ciudad la carne y pescado con la abundancia que en los arcabucos, lagunas y ladroneras suyas ... (FIGUEROA, 1986 [1661], p. 163164).

Mucho trabajo ay, y tiene la caridad y zelo de los padres buena material y lugar en qué exercitarla, armándose de paciencia: (...) y aunque es todas aquestas naciones, es mucho más en la de los maynas, por ser tan amigos de huirse y huir de los españoles, con quienes están como biolentados y aburridos, y cuyos bautismos es fuerça hazerlos en breve tiempo, porque no tienen lugar ní comodidad de gastar mucho en disponerse y deprender las oraciones, como ay en las otras reducciones que no tienen sobre sí el embaraço de las ocupaciones en que los ponen los españoles, ni la incomodidad de Borja y sus tambos y estancias en que tienen sus pueblos divididos... (FIGUEROA, 1986 [1661], p. 165).

Dessa forma, se eles viviam como brutos, a dominação espanhola os brutalizava mais ainda, gerando fugas constantes e grandes levas de índios cimarrones, isto é, fugitivos que, "en sus ladroneras" se apartavam ainda mais dos preceitos de vida cristã: esquecendo "de lo que savian, se entorpezen (...) como exercitados en la vida de brutos y fieras". Esta situação colocava em risco e desestabilizava, não apenas o esforço de conversão, como a própria existência dos povoados e sobrevivência dos colonos, "anocheciendo muchas vezes com encomienda y amaniecendo sin ella, despojados de herramientas, canoas y otras cosas, y sin tener quién los substente y sirba" (FIGUEROA, 1986 [1661], p. 164).

As missões volantes, por sua vez, não se mostravam suficientes para 
solidificar a fé dos neófitos. A fundação, por De la Cueva, de Limpia Concepcion de Jéberos em 1638, dará início a um novo procedimento por parte dos padres: a congregação dos índios em povoados. Depois deste, será constituída uma série de outros deles, buscando reduzir - de acordo com o Informe - além dos já citados jeberos, os cocamillas, os cocamas e paranapuras., os mayorunas, os aguanos, entre outros. ${ }^{15}$

A origem de Limpia Concepcion contudo, sinaliza de forma clara a profunda ambiguidade a que se via sujeita a missão dos jesuítas no Alto Amazonas. De la Cueva realiza seu contato com os jeberos em um acampamento - um real - de soldados que estão em perseguição aos maynas fugitivos. Ainda que denominados como "índios amigos", "nervio principal de esta milícia”, (Carta do padre De la Cueva, de 16 de abril de 1638. In: FIGUEROA, 1986 [1661], p. 171), os jeberos são descritos como verdadeiramente aterrorizados diante das atrocidades cometidas sobre os rebeldes em nome "justiça" dos espanhóis. Apesar de aliados dos soldados, os índios manifestam desconfiança e receio para com eles, situação que estimula o jesuíta a acenar-lhes com a proposta de congregarem-se em um povoado em que estariam protegidos.

A expedição de De la Cueva em busca das rancherias onde estariam os demais jeberos, é acompanhada por escolta de soldados espanhóis, situação que nunca foi incomum na Amazônia. As "entradas" em territórios novos, deviam ocorrer com o acompanhamento de escolta militar segundo determinação do próprio vice-rei do Peru. Esta, "al mismo tiempo ayudava a los religiosos en el translado de los indígenas a los poblados (...) para iniciar su cristinización y de manera concomitante, su (...) permanecia estable en un poblado" (NEGRO, 1999, p. 273).

\section{Os "pueblos", os índios e padres:}

Como já afirmamos, durante o tempo em que existiu, a Missão de Maynas enfrentou graves e variadas dificuldades, que iam das enormes distâncias em um ambiente que era hostil aos missionários, ao número sempre insuficiente de religiosos ${ }^{16}{ }^{16}$ dada à extensão do território e dispersão da população indígena. ${ }^{17} \mathrm{~A}$ necessidade dos padres se deslocarem entre os três ou quatro povoados que lhes eram destinados, determinava uma falta de sistematicidade que era, também, 
prejudicial à estabilidade dos mesmos. Há que se referir, ainda, à multiplicidade das etnias e especialmente das línguas locais, quase sempre desconhecidas dos religiosos, e ao insucesso das tentativas de transformar o quéchua em língua geral para comunicação entre padres e índios. De fato, a imensa maioria dos nativos jamais aprendeu a "língua do Inca", e a necessidade de intérpretes na comunicação foi constante. Somava-se a estas dificuldades variadas, a própria resistência demonstrada pelos grupos indígenas, que manifestavam perene suspeição em relação aos espanhóis e aos próprios padres.

Algumas características sobressalentes dos grupos indígenas da região tiveram forte repercussão quanto às singularidades assumidas pelas reduções de Maynas, quanto ao tipo de trabalho que os jesuítas conduziram e ainda sobre os resultados de sua prática missionária.

Nesse sentido, destacaremos aqui três destas questões, sendo a primeira delas, a segmentação das sociedades amazônicas. Na carta de 16 de abril de 1638 em que descreve a fundação de Limpia Concepción de Jeberos, a primeira das reduções de Maynas, o Padre Lucas de Cueva, depois de relatar as dificuldades de localizar as aldeias escondidas na mata, ${ }^{18}$ registra:

Fui caminando por buen camino, enjuto y tieso, á la primer ranchería. El día siguiente á la del cacique principal. Ni á el, ní a su hermano, ni á otros indios de séquito los hallé, con que pude assentar poco en órden á su población y dotrina, que parece abrá de dar no poco trabajo, por la gran division en que está toda esta nación, repartida en varias rancherías, distantes entre sí dos, quatro y seis leguas; algunas tres y quatro jornada (FIGUEROA, 1986 [1661], p. 178).

As formas pelas quais se organizavam estas sociedades, portanto, "repartidos em rancherias", cada qual com sua liderança particular, era estranha e inconveniente aos propósitos dos padres. Sobre isto, o Informe diz ainda, que custou tempo e trabalho convencer aos jeberos sobre a necessidade que "que se poblassen juntos, cosa tan repugnante á la inclinación destas Naciones" (FIGUEROA, 1986 [1661], p. 181).

Depois, comentando as dificuldades experimentas pelo Padre Lucas de la Cueva ele anota: 


\begin{abstract}
Prosiguió el padre con esta Nacion haciendo en ella otras entradas en órden á su reduccion, no con otro fruto que andar en varias correrías á las caserías tan divididas de los indios, a lo que se ofrecia de enfermos, achacosos y viejos, para su instrucción y bautismo. En su reducción se obrava poco, porque cada qual queria se hiciesse la población en su ladronera, que tienen por su patria, de que se ausentan con grandísima repugnancia; con que aunque se les hacian varios razionamentos, no surtia la cosa (FIGUEROA, 1986 [1661], p. 178-179).
\end{abstract}

O nomadismo, o gosto dos índios pelos "paseos largos" constituía-se em outro dado da sua cultura que se apresentava como problemático para as pretensões dos missionários. Finalmente, seguindo, ainda as ponderações de Figueroa, encontramos um terceiro elementos para compor o quadro das dificuldades enfrentadas pela Missão de Maynas, que se refere ao escasso número de sacerdotes e sua decorrente necessidade de atender a mais de uma redução.

A dispersão dos índios, e o desejo dos missionários de encontrar e reduzir novos grupos, podiam ser inconvenientes perigosos para o trabalho junto aos já aldeados. Adverte Figueroa que o afastamento dos padres trazia repercussões indesejadas, dada a "natureza" dos índios, em quem não "assienta ni arraiga la fee", necessitando de "contínuo regadio de quien la predica".

$Y$ es tal la calidad de este gentío, que teniendo padre que les asista, se pueblan, moran en sus pueblos y obran lo que les importa: en faltándoles al padre, se desparraman como ganado sin pastor, por la natural inclinación que tienen á paseos largos y á sus ladroneras antiguas y modo de vivir distantes unos de los otros, y á sus barbaridades, que las vuelven á ejercitar fácilmente en viéndose sin quien les corrija y mire" (FIGUEROA, 1986 [1661], p. 181-182).

Pode-se perceber daí, que os jeberos parecem dispostos a negociar suas práticas nômades e assentarem-se nos povoados, sempre que isto - a proximidade dos padres - lhes pareça uma garantia contra as arbitrariedades dos povoadores espanhóis. A ausência dos padres, contudo, ainda que temporária, 
funciona de modo contrário, e obriga os jesuítas a novos e constantes esforços de convencimento, a um repetido trabalho de conquistar e reconquistar a adesão dos índios:

Esta plaga general, calidad destos desdichados, la han tenido los xeberos, pues quatro ó cinco veces que al padre le ha sido forçoso hacer ausencia á Quito, á Lima y a otras partes por negocios de la misión, los há conquistado de de nuevo... (FIGUEROA, 1986 [1661], p. 182).

Os jesuítas desacreditam da constância dos índios na fé que lhes é apresentada na missão. Por sua vez, a desconfiança também era presença constante entre os índios, perturbando a qualidade da relação que os sacerdotes pretendiam construir com seus catecúmenos. Dessa forma, assim como foi a partir do temor aos espanhóis que os sacerdotes conseguiram convencer os jeberos a construir as missões e a se radicar nestes povoados, o medo também era capaz de operar em favor do seu abandono. A suspeita sobre os padres e suas intenções podia surgir a partir da palavra dos "viejos y mohanes" (feiticeiros) que alertavam aos demais sobre os perigos de que:

[...] el reducirlos los padres á población era para darles la muerte, ó por lo menos para entregarlos á la servidumbre de los españoles; quando veían al padre rezar y santiguarse, decían que con aquellas señales llamaba, desde sus tierras, á los españoles; y a este modo, otras boberías que á su discurso les parecían fuertes argumentos en sus temores (FIGUEROA, 1986 [1661], p. 180).

Os povoados estiveram sempre na órbita da colonização espanhola, numa esfera que era suficiente para alimentar a desconfiança dos índios relativamente aos jesuítas. Segundo Taylor (1992, p. 219), “o apelo aos jesuítas lançado em 1664 pelo governador de Borja marcou o nascimento dessa relação ambígua, ao mesmo tempo conflituosa e simbiótica". Sua faceta conflituosa residia em que ambos eram agentes da colonização buscando construir ascendência sobre os mesmos índios. De outra parte, simbiótica porque foi a pressão constante dos colonos que conduziu para a esfera de ação dos padres, índios de outra forma muito reticentes a se deixarem reduzir. "Uns não podiam se reproduzir 
sem os outros, e todos se sentiam constantemente ameaçados pelos interesses do vizinho" (TAYLOR, 1992, p. 220). Sem dúvida, a dependência que se estabelecia entre eles e as milícias espanholas não contribuía para solucionar esta questão Os missionários tinham muita clareza da precariedade de sua situação e temiam por ela. Reconhecem, portanto, que ainda que "algunos dones y (...) utilidades que se les proponen” (FIGUEROA, 1986 [1661], p. 248) sejam de valor, não pode ser desmerecido o papel desempenhado pelo medo, presente desde as primeiras manobras para reduzir os jeberos.

A fragilidade das alianças estabelecidas fica muito evidente quando da rebelião ocorrida cinco anos depois de iniciada a redução, tendo os índios abandonado o povoado e deixado o padre De la Cueva entregue a sua própria sorte. Segundo o Informe, estando adiantado o trabalho de instrução religiosa e especialmente de batismo, “se lebantó um torbellino', especialmente potencializado pela ação de alguns maynas em visita ao povoado, os quais semearam o medo entre os jeberos, afirmando-lhes que os registros de batizado serviriam para os espanhóis pô-los sob o regime de encomienda (FIGUEROA, 1986 [1661], p. 182).

Andaban con estos discursos y pláticas, y el padre nada sabía: quando una noche, á la mitad de ella, media hora despues de recogido el padre, lebántase de repente un loco alboroto en el pueblo, y comienzan á huir deshalados, unos por una parte, otros por otra... Por la mañana vió su pueblo casi todo despoblado, y á pocos dias lo quedó del todo, porque se fueron todos, ... (FIGUEROA, 1986 [1661], p. 183).

Depois de algum tempo os fugitivos retornaram presionados pela perseguição das milícias brancas e da ameaça contra todos "los que hallasse fuera de sus pueblos", que seriam levados para Borja "á que serviessen á los españoles". Os espanhóis buscaram os rebeldes "por los rios y retiradas", capturando "á los rehacios (...) que no trataban de irse á sus pueblos, executando lo que (...) se les abia amenazado" (FIGUEROA, 1986 [1661], p. 185).

Segundo Londoño (2006), como já tinha acontecido com os Maynas, a guerra e o terror das forcas se faziam necessários como poder de persuasão para promover a sujeição. Figueroa parece estar bastante consciente do papel 
desempenhado pelo medo como instrumento para sujeição (LONDOÑO, 2006), registrando que, anos depois, ainda tremiam os índios de pavor diante da lembrança das forcas que haviam sido levantadas no praça da redução, castigo do qual teriam sido salvos pela intervenção dos jesuítas: "si bien el que merecian de muerte pareció por entonces, y estar las missiones tan tiernas em sus princípios, que bastaba para su correcion y aviso, dársela á tragar en las forcas, intercediendo los padres pra librarlos" (FIGUEROA, 1986 [1661], p. 188). Mais adiante em seu relato, refletindo sobre a "disposição" encontrada entre as nações do Marañón para receber o Evangelho, afirma com clara compreensão que: "No deja de ayudar para ello el temor que tienen al español" (FIGUEROA, 1986 [1661], p. 248).

Apesar disso contudo, uma observação atenta daquilo que recolhe o missionário em seu texto, revela o que mais parece uma negociação entre padres, espanhóis e índios, do que uma rendição total destes últimos. Os jeberos ${ }^{19}$ recebem o perdão das autoridades, mas também algumas concessões que lhes são bastante favoráveis, como a isenção das obrigações de tributo e trabalho. A contrapartida para selar esta aliança com o poder colonial, foi a de que auxiliassem no contato com outros grupos, ${ }^{20}$ contribuindo para o avanço do território de missionação, bem para resguardo das povoações espanholas ${ }^{21}$ na área.

Portanto, ao lado do terror, as concessões de parte a parte, parecem ter desempenhado papel de relevo nessa história, o que se observa, ainda, em outras situações que se estabelecem para garantir a continuidade dos povoados e da missão. Os índios não abandonam de todo seus hábitos nômades, e os padres se obrigam a autorizar as ausências: "aun para sus passeos en tiempo de tortugas y frutas, pescas y otras cosas necessárias á su sustento, piden licencia al Padre, quien les señala los dias que han de tardar, ..." (FIGUEROA, 1986 [1661], p. 190). Mesmo as execradas bebedeiras acabaram tendo que ser toleradas, embora o missionário racionalize o fato afirmando que - dado que o teor alcoólico de suas bebidas não era muito forte e que este era seu costume desde muito jovens - os jeberos raramente ficavam embriagados. Desta forma, podiam os padres conceder que fizessem uso delas, ordinariamente aos domingos "y no passan de la hora em que les tocan las Ave-Marías" (FIGUEROA, 1986 [1661], p. 190). 
A imposição pela força nunca esteve fora desse horizonte de possibilidades, como, por exemplo, na captura de índios que, feitos ladinos, deveriam ser os intermediários entre os padres e seus grupos. Mas, também, na confiança de que o temor à Justiça dos espanhóis servisse de estímulo à aceitação da presença de padres entre eles. Dessa forma, as esferas de ação civil e religiosa estavam perigosamente aproximadas e dependiam, de fato uma das outra:

... con la doctrina y persuasiones de los padres y con el braço de la justicia, necessário y forçoso, dándose las manos el Evangelio en la enseñanza, y la justicia en castigar y reprimir desafueros y delitos que los padres no pueden por si só remediar ni castigar, pues no son juizes ni berdugos para ahorcar ni executar otros castigos, que si no los hace la justicia secular, quedarón los males sin remédio (FIGUEROA, 1986 [1661], p. 248).

Tal proximidade, sem dúvida, contribuía para alimentar a prevenção dos nativos para com os sacerdotes, e para a crença, por parte dos primeiros, de que estes "los sacaban de los montes à morirse y consumirse". Também de que as listas de batismo serviam para distribuir "encomiendas", e de que, se os juntavam em povoados, era "para entregarlos á los españoles" (FIGUEROA, 1986 [1661], p. 252). Pode-se observar contudo, que o clima de suspeição era mútuo. É assim que, provavelmente angustiado diante das tremendas conseqüências desencadeadas pelas pestes que assolavam as aldeias em situação de contato com os brancos, Figueroa reflita que este poderia ser um castigo divino para quem "oyendo el nombre de Christo y su santa ley, dehen de rehusar el recebirla, ó no la reciben de coraçon, sino fingidamente, y si quieren recibirla ha de ser reteniendo juntamente sus aboninables costumbres...”(1986 [1661], p. 252).

Assim, entre o temor e a desconfiança, de uns e outros, e a necessidade de operar nas circunstâncias desta região de fronteira - fronteira entre poderes, entre horizontes simbólicos, entre esperanças e desejos também -, a Missão de Maynas enfrentou a necessidade de fazer-se e refazer-se constantemente, de acordo com o que era possível - aos padres e aos índios - aceitar, negociar ou recusar. 


\section{Notas}

1 Esta é uma versão revista e revisada de trabalho apresentado no Primeiro Congresso Internacional Chiquitano, San Ignácio de Velasco, Bolívia, 22 a 24 de maio de 2008.

${ }^{2}$ É esta a grafia utilizada pelo padre. Francisco de Figueroa, missionário jesuíta e autor do Informe de 1659-1661 sobre estas Missões.

${ }^{3}$ No âmbito civil, os padres da missão subordinavam-se à Audiência de Quito]

${ }^{4}$ Lucas de Cueva era andaluz, enquanto Gaspar de Cugia era natural da ilha de Sardenha (Santos, 1992, p. 224).

${ }^{5}$ Sobre Limpia Concepción de Jeberos, Figueroa informa que "tiene esta reducion três anejos donde acude á ella la gente los domingos y fiestas á oir missa, dotrina y sermón. Son el de San Pablo de Pambadeqeus (que tambien llaman Guallagas), el de Santo Thomé de los Cutinanas y el de San Joseph de los Ataguates, todos con iglesia y campana, donde rezan y dice missa el padre quando ba á sacramentear á alguno. Por todos llegan á ochocientas personas, rebaja á que les han traydo las repetidas pestes, de mil y seiscientos que eran" (Figueroa, 1986 [1661], p. 191).

${ }^{6}$ Esta instituição é proveniente da experiência castelhana na Guerra de Reconquista e foi também utilizada nas primeiras colônias nas Canárias. Na América, a "encomienda" foi adaptada ás situações locais, tendo por objetivo garantir contribuições de mão de obra indígena ou o pagamento de tributos aos espanhóis. No primeiro caso, envolvia a concessão temporária de indígenas confiados (encomendados) aos cuidados de um colono que ficava responsável por sua proteção e catequese. Este encomendeiro tinha, em troca, o direito de solicitar aos índios uma compensação na forma de prestação de serviços. Embora tenha sido concebida como um dispositivo legal para disciplinar o acesso dos colonos ao trabalho dos índios, esta instituição deu lugar a práticas abusivas e várias irregularidades, haja vista a dificuldade de controlar sua aplicação. Motivou ainda, expedições armadas para captura de novos indígenas, sempre que os já incorporados eram insuficientes para atender às necessidades dos colonizadores. Contida, disciplinada e, por fim, suprimida nas regiões mais centrais e mais densamente povoadas, as encomendas sobreviveram nas regiões periféricas, menos ricas, e em que a mão de obra indígena era a maior riqueza para os colonos.

${ }^{7}$ De fato, como lembra Londoño, muitos destes povoadores eram já nascidos na América e a utilização do termo "espanhóis" em referência a eles, justifica-se apenas pelo objetivo de distingui-los dos índios. Ver: Torres-Londoño, 2007, p. 195.

${ }^{8}$ Figueroa nasceu em Popayán, Nova Granada, por volta de 1607, ingressando na Companhia em 1630. Depois de aprender o quéchua, que os jesuítas pretendiam fosse língua geral para a catequese dos povos amazônicos, ele foi enviado para San Francisco de Borja, onde chegou em 1642. O seu Informe sobre as missões de Maynas, onde atuou desde 1642, tendo sido seu Superior entre 1656 e 1665, foi escrito atendendo a uma solicitação do Provincial padre 


\section{Hernando Cavero.}

${ }^{9}$ As duas últimas, Santiago e Santa Maria de las Nieves se converteriam, mais tarde, em importantes postos avançados para o desenvolvimento das missões jesuíticas.

${ }^{10}$ Solicitação encaminhada para o vice-rei Francisco de Borja y Aragon (1615 - 1621).

${ }^{11}$ O Informe reporta-se a uma série de epidemias que tinham reduzido severamente a população de maynas. De acordo com ele, no início dos contatos, os maynas eram em torno de 700 tributários; em 1638 seu número caíra para 400. Em 1661, época da redação do texto, estavam reduzidos a mais ou menos 200 tributários (FIGUEROA, 1986 [1661], 160).

${ }^{12} \mathrm{O}$ jesuíta não se furta de criticar a este respeito, aos espanhóis que haviam posto nomes cristãos em seus índios de serviço, sem de fato batizá-los; diz ainda que outros tantos tinham sido batizados, sem receber a necessária instrução cristã. Critica, por fim, aos curas que haviam estado na cidade antes da chegado dos inacianos, por não terem se empenhado em mudar a situação. Ver: Figueroa, 1986 [1661], p.161.

${ }^{13} \mathrm{O}$ padre. Cugia que iniciou o trabalho teve que se valer de intérpretes, "de que ya avia muchos enseñados entre los españoles y ladinos en lengua del Inga”, reunindo grupos, predicando-lhes e ensinando o catecismo duas vezes ao dia (FIGUEROA, 1986 [1661], 162).

14 "La causa es el irse los maynas frecuentemente (...) por ser ellos criados en la vida ancha y ociosa de los montes, sin sujeción a nadie, amicíssimos de passearse, y de andar de unas partes á otras,..” (FIGUEROA, 1986 [1661], 163-164).

${ }^{15}$ Segundo Fernando Torres Londoño, O padre Rodríguez informa sobre a existência de 13 pueblos até o ano de 1666: Limpia Concepción de Xeberos, San Pablo de los Pambadeques, San Ioseph de los Ataguates, Santo Tomé de los Cutinanas,Santa María de Guallaga, Nuestra Señora de Loreto de Paranapura, Santa María de Ucayale, San Ignaciode los Barbudos, San Xavier de los Aguanos, Angeles de Roamaynas, San Antonio, San Salvador de losZapas y Iesus de los Coronados. Em uma outra relação para o ano de 1684 relaciona dezenove pueblos: San Luis Gonzaga de Maynas, San Ignácio de Maynas, Santa Teresa de Iesús de Maynas, Los Ángeles de Roamaynas, Iesús de los Coronados, San Francisco Xabier de los Gayes, Concepción de Xeberos, Nuestra Señora de Loreto de Paranpuras, anexos de Chayavitas y Muniches, Santa María de Ucayales, Santiago de Xitipos y Chepeos, San Lorenço de Tibilos, San Xabier de Chamicuros, San Antonio Abad de Aguanos, Santa María de Guallaga, San Joseph de Maparinas, San Ignacio de Mayuranas y San Estanislao de Otanavis. Torres Londoño explica a ausência de vários dos pueblos, constantes na primeira relação e desaparecidos na segunda, a partir da instabilidade de muitos assentamentos, que não chegavam a perdurar por muito tempo. Igualmente lembra que, em alguns casos, reduções podiam ser abandonadas para fundarem-se novos agrupamentos. Ver: Torres-Londoño, 2006, p. 43.

${ }^{16}$ Ao serem os jesuítas detidos e expulsos em 1768, 41 missões de Maynas então existentes, eram atendidas por 28 padres da Companhia.

17 "El embarazo mayor que hay es el ser algunas naciones muy pequeñas y vivir en partes tan inhabitables y remotas para la comunicación, que nos es posible humanamente puedan vivir en ellas sacerdotes". A solução percebida pelos missionários, que era "sacar los tales indios 
á donde puedan morar con dotrina y comunicación, y ser corregidos y dirigidos", não era a desejada pelos nativos (FIGUEROA, 1986 [1661], p. 202).

${ }^{18}$ A leitura do Informe do padre Figueroa não deixa dúvidas sobre as enormes e trágicas repercussões do domínio espanhol sobre as populações indígenas, bem como sobre a forma como estas procuravam colocar-se a salvo do contato com os brancos valendo-se para tanto do seu conhecimento do ambiente.

${ }^{19} \mathrm{O}$ mesmo valeu para seus aliados, os cocamas de Guallaga (cocamillas) e os paranápuras.

20 "Despues destos lances han quedado los xeberos tan assentados (...) y son los más fieles para los padres y españoles, sirbiéndoles con fidelidad en las armadas y descubrimientos que se hacen para pacificar nuevas naciones y reducirlas al Santo Evangelio, y están por particular merced reserbados de mita y tributo, dedicados solamente á las cosas de guerra y servicio de los padres en lo tocante á descubrimientos y reducciones" (FIGUEROA, 1986 [1661], p. 188). "mediante estos indios se ha procurado solicitar otras naciones (...). Assí lo hacieron con los cutinanas (...). Trataron de irles á hablar, dándose por parientes dellos, en órden á traerlos á esta reducción de Xeberos, con licencia que tenían de la justicia y del padre, porque combiene que semejantes acciones no las hagan sin esas licencias y registros" (FIGUEROA, 1986 [1661], p. 188). A conveniência à que se refere o jesuíta sobre "licença e registro" para suas investidas, sugere as latentes suspeições às quais temos nos referido.

21 "Y son como frontera que tiene la ciudad para su resguardo y de los padres, para que otras gentes no se atreban á intentar alzamientos y barbaridades, porque ben que tienen los españoles gente fiel de quien balerse quando los intenten" (FIGUEROA, 1986 [1661], p. 188).

\section{Referências}

BOXER, Charles Ralph. A igreja e a expansão ibérica (1440-1770). Lisboa, ed. 70, 1981.

CUNHA, Manuela Carneiro da. História dos Índios no Brasil. São Paulo, Companhia das Letras, 1992.

FIGUEROA, F. Ynforme de las Misiones en el Marañón, Gran Pará o Río de las Amazonas por el padre Francisco de Figueroa, 1661. In: CETA. Informes de Jesuitas en el Amazonas (1660-1684). Iquitos: Monumenta Amazónica, 1986. KERN, Arno \& JACKSON, Robert. Missões ibéricas coloniais: da Califórnia ao Prata. Porto Alegre: Palier, 2006.

MELIÁ, Bartomeu. Missão por Redução. Estudos Leopoldenses, História 3, v. 25, n. 110, 1989. p. 21-36, maio/jun.

NEGRO, Sandra \& MARZAL, Manuel (Coord.). Un reino en la frontera. Las misiones jesuitas en la América colonial. Lima: Pontificia Universidad Católica del 
Perú. PUCP, 1999.

NEGRO, Sandra. Maynas, una misión entre la ilusión y el desencanto. In: NEGRO, Sandra \& MARZAL, Manuel. Un reino en la frontera. Las misiones jesuiticas en la América colonial. Lima/Quito. PUCP, E. Abya-Yala, 1999.

RODRIGUEIRO, Jane. Tensão e redução na várzea: as relações de contato entre os Cocama e Jesuítas na Amazônia no século XVII 1644-1680. Dissertação (Mestrado em História) - Pontifícia Universidade Católica de São Paulo, 2007. SANTOS, Angel. Los Jesuitas em América. Madrid: MAPFRE, 1992.

TAYLOR, Anne Christine. História Pós-colombina da Alta Amazônia. In: CUNHA, Manuela Carneiro da. História dos Índios no Brasil, São Paulo, Companhia das Letras, 1992, p. 213-238.

TORRES LONDOÑO, Fernando. Contato, guerra e negociação: redução e cristianização de Maynas e Jeberos pelos jesuítas na Amazônia no século XVII. História Unisinos, v. 4, 2007, p. 192-202.

- Trabalho indígena na dinâmica de controle das reduções de Maynas no Marañon do século XVII. História (São Paulo), v. 25, 2006, p. 15-43. 